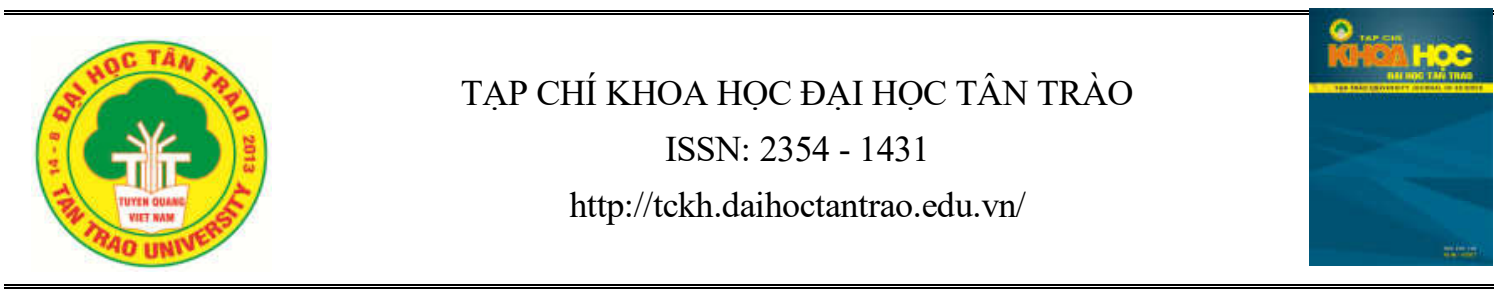

\title{
Những vấn đề cơ bản cho du lịch Lâm Bình phát triển
}

\author{
Dương Văn Sáu ${ }^{a^{*}}$ \\ ${ }^{a}$ Truờng Đại học Văn hóa Hà Nội \\ *Email:saudv@huc.edu.vn
}

\section{Thông tin bài viết}

Ngày nhận bài:

12/11/2019

Ngày duyệt đăng:

$10 / 3 / 2020$

Tù khóa:

Du lịch Lâm Bình; phát triển du lịch Lâm Bình

\section{Tóm tắt}

Lâm Bình - huyện miền núi, vùng sâu, vùng xa, vùng cao của tỉnh Tuyên Quang với rất nhiều tài nguyên phong phú để có thể khai thác để phát triển du lịch. Cho đến nay, du lịch Lâm Bình chưa phát triển. Đó là một thách thức, đồng thời là một cơ hội lớn cho kinh tế du lịch của huyện phát triển. Ở cửa ngõ của sự phát triển, Du lịch Lâm Bình cần có những bước đi chính xác, chắc chắn, có tầm chiến lược lâu dài, có cơ chế chính sách thích ứng để thu hút đầu tư, tạo ra những thay đổi căn bản trên các lĩnh vực lớn: Giao thông vận chuyển thủy bộ - Cơ sở lưu trú du lịch - Xây dựng sản phẩm du lịch đặc trưng - Đào tạo nâng cao chất lượng nguồn nhân lực - Liên kết phát triển đồng bộ... Đó là những yếu tố quyết định sự phát triển của Du lịch lâm Bình trước mắt cũng như lâu dài.

\section{1. Đặt vấn đề}

Tiềm năng cho phát triển của Du lịch Lâm Bình rất lớn. Ở thời điểm hiện tại Du lịch Lâm Bình chưa phát triển, đang phát triển. Chính điều này vừa là khó khăn nhưng cũng lại là một thuận lợi cho sự phát triển của Du lịch Lâm Bình về lâu dài. Khó khăn là Du lịch chưa phát triển, tài nguyên chưa được khai thác hiệu quả, chưa tạo ra nguồn lực mạnh khiến cho kinh tế du lịch của huyện chưa phát triển, còn gặp nhiều khó khăn, thách thức trên nhiều lĩnh vực. Nhưng đây cũng chính là những thuận lợi căn bản, là cơ hội, thời cơ cho $\mathrm{Du}$ lịch Lâm Bình cất cánh, phát triển nhanh chóng. Ở cửa ngõ của sự phát triển, Du lịch Lâm Bình có cơ hội tiếp cận cái mới, có cơ hội được thực thi đường lối, cơ chế, chính sách, giải pháp mới mà chưa bị "vướng" những hạn chế đã có. Cái phông phát triển của Du lịch Lâm Bình còn tinh khôi, chưa bị chi phối, vướng cản bởi những hạn chế đã có. Điều đó là một thuận lợi lớn cho cơ hội phát triển nhanh chóng, vững mạnh trên nền tảng của tài nguyên tự nhiên và tài nguyên văn hóa phong phú. Vấn đề bây giờ là đường lối phát triển, bước đi và biện pháp đúng đắn, đồng bộ, có tầm chiến lược lâu dài; cơ chế chính sách thông thoáng, hợp lý, hài hòa... sẽ tạo cho Du lịch Lâm Bình phát triển nhanh chóng và bền vững.

Trước khi đưa ra những gợi ý về bước đi và giải pháp cụ thể cho Du lịch Lâm Bình phát triển, chúng ta cần nhận thức rõ 6 vấn đề cơ bản có liên quan đến du lịch và kinh doanh du lịch sau đây:

Thư nhất, Lâm Bình với rất nhiều tài nguyên phong phú có thể khai thác để phát triển du lịch. Cho đến nay, Du lịch Lâm Bình chưa phát triển; đang phát triển theo định hướng chiến lược của Đảng bộ và nhân dân các dân tộc Lâm Bình. Ở cửa ngõ của sự phát triển, Du lịch Lâm Bình có cơ hội tiếp cận cái mới, có cơ hội được thực thi đường lối, cơ chế, chính sách, giải pháp mới mà chưa bị "vướng" những hạn chế đã có. Cái phông phát triển của Du lịch Lâm Bình còn tinh khôi, chưa bị chi phối, vướng cản bởi những hạn chế đã có. Do vậy, Du lịch Lâm Bình cần có những bước đi chính xác, chắc chắn, có tầm chiến lược lâu dài, có cơ chế chính sách thích ứng để thu hút đầu tư, tạo ra những thay đổi căn bản trên các lĩnh vực lớn. Du lịch Lâm Bình đang ở cửa ngõ của những cơ hội lớn!

Thú hai, Du lịch là quá trình kết nối những không gian và thời gian nhất định thông qua những dịch vụ 
xác định. Muốn có dịch vụ xác định, ngoài yếu tố con người còn rất cần phải có sự đầu tư cơ sở hạ tầng phù hợp. Dịch vụ thuộc Động - Hạ tầng thuộc Tĩnh: cần phải có sự cân đối giữa Động và Tĩnh, phát triển Động trên nền tảng Tĩnh mới tạo ra sự phát triển bền vững. Do vậy huyện cần đầu tư, kêu gọi đầu tư cho cơ sở hạ tầng du lịch từ nội lực và ngoại lực.

Thú $b a$, Du lịch là ngành kinh tế dịch vụ tổng hợp nên muốn du lịch phát triển phải phát triển các dịch vụ đồng bộ. Quan trọng hơn là phải kết nối các dịch vụ đó trong nội vùng điểm đến đồng bộ, tiếp đến liên kết ngoại biên tạo nên sự liên hoàn mang tính hệ thống.

Thư $t u$, Du lịch là quá trình tìm kiếm ấn tượng và sự khác biệt của các đối tượng du khách. Muốn tạo sự khác biệt thì người cung ứng hãy là chính mình. Giữ bản sắc Lâm Bình, hãy là chính mình với những bước đi riêng, cách làm riêng mới tạo nên ấn tượng và sự khác biệt. Từ đó sẽ tạo ra lợi thế cạnh tranh của du lịch Lâm Bình so với các địa phương bạn.

Thư năm, Du lịch muốn phát triển cần phải đạt được, tạo ra sự hội nhập cả hai khía cạnh chung và riêng. Chung là thông lệ quốc tế, chuẩn nghề, chuẩn ngành cần được phổ cập, áp dụng; Riêng là truyền thống và bản sắc địa phương, dân tộc cần được củng cố, giữ vững.

Thú sáu, Kinh tế du lịch nếu nói ngắn gọn bằng một (1) từ thôi, thì đó là từ ĐộNG. Động tức là dịch chuyển, dịch chuyển là thay đổi, biến đổi không ngừng tạo ra sự phát triển. Vậy nên, muốn phát triển kinh tế $\mathrm{Du}$ lịch Lâm Bình cần có những bước đi và biện pháp đúng đắn, quyết liệt, đồng bộ, cụ thể triển khai quá trình "Lục biến (六变): biến đổi/thay đổi" trong hoạt động kinh doanh du lịch trên nền tảng dựa vào kho tàng di sản văn hóa và di sản thiên nhiên phong phú trên mảnh đất Lâm Bình, bao gồm:

1. Biến di sản thành tài sản.

2. Biến văn hóa thành hàng hóa.

3. Biến tài nguyên thành tài chính.

4. Biến nguồn lực thành động lực.

5. Biến môi trường thành thị trường.

6. Biến giá trị thành giá cả.

Tất cả những thay đổi trong quá trình triển khai “luc biến (六变)" kể trên đều là những công việc cụ thể nằm trong hai quá trình “song hóa (雙化)" (2 quá trình thay đổi song song, đồng thời), là: Kinh tế hóa Văn hóa và Văn hóa hóa Kinh tế trong hoạt động du lịch. Quan điểm "Lục biến (六变)" nêu trên chính là việc triển khai các nhiệm vụ cụ thể trong các khâu công việc của quá trình kinh doanh du lịch. Đó chính là quá trình triển khai những nhiệm vụ cụ thể, thực thi hành động trong quá trình bảo tồn, khai thác, phát huy giá trị của di sản văn hóa dân tộc qua con đường du lịch trên địa bàn huyện Lâm Bình hiện nay. Bao trùm lên hết thảy, vấn đề quan trọng nhất của Du lịch Lâm Bình hiện nay là "Biến giá trị thành giá cả". Tài nguyên du lịch của Lâm Bình rất giá trị, phải làm thế nào để đưa những giá trị phong phú, đặc trưng này đem lại những giá cả được nâng cao, mang lại lợi ích, lợi nhuận phù hợp cho người kinh doanh? Đây là câu hỏi lớn nhất cho công việc phát triển Du lịch Lâm Bình hiện nay? Để góp phần trả lời cho câu hỏi trên, chúng tôi đưa ra mấy gợi ý cụ thể sau đây:

\section{Những gợi ý cho phát triển du lịch Lâm Bình}

Du lịch là ngành kinh tế tổng hợp nên muốn phát triển Du lịch Lâm Bình cần phải phát triển đồng bộ nhiều thành tố, nhiều góc độ, mức độ bắt đầu từ xây dựng đường lối chính sách đúng đắn; cơ chế thích hợp, khoa học; đến xúc tiến đầu tư đồng bộ, kịp thời; xây dựng sản phẩm đặc trưng; đào tạo nguồn nhân lực chất lượng cao; quảng bá truyền thông tốt; liên kết rộng; thanh kiểm tra chặt chẽ, phát triển thị trường, chăm sóc khách hàng hậu mãi.v.v... Sẽ có rất nhiều công việc phải tiến hành đồng bộ, kịp thời. Trong khuôn khổ bài viết này, tôi sẽ trình bày một vài khía cạnh trên quan điểm, nhìn nhận, hiểu biết của cá nhân để góp thêm tiếng nói, góp phần tăng thêm những thông tin định hướng về du lịch Lâm Bình để các nhà quản lý, hoạch định chính sách tham khảo trước khi đưa ra quyết định...

\subsection{Phát triển giao thông vận chuyển thủy bộ} liên hoàn đăc thù

- Du lịch là chuyển dịch, muốn vậy giao thông vận chuyển giữ vai trò quyết định. Cần mở rộng và củng cố các trục đường giao thông kết nối Lâm Bình với Chiêm Hóa - Na Hang và Bắc Mê (Hà Giang). Trên các trục đường này cần xây dựng các "Vọng sơn đài", các điểm dừng chân, quan sát, ngắm cảnh, chụp ảnh, vệ sinh cá nhân, mua sắm sản vật địa phương, tiếp nhiên liệu cho ô tô, xe máy, kiểm tra tình trạng kỹ thuật của phương tiện vận chuyển. Phát triển các dịch vụ tự phục vụ cho du khách ven các đường giao thông. Ví dụ trên con đường nối Lăng Can (Lâm Bình) với Bắc Mê (Hà Giang) khi đã mở đường, trải nhựa, bê tông sẽ cần thiết kế, xây dựng ở đỉnh đèo Khau Cau điểm check in ấn tượng với cây Nghiến cổ thụ. Chọn 
vị trí, xếp đá, tu sửa cảnh quan... giúp cho du khách có điểm selfie thuận lợi. Trên địa bàn xã Phúc Yên, bổ sung các điểm dừng chân ven đường, ven suối nơi chỗ có cảnh đẹp, có suối và cầu treo, có cây vối, có ruộng nương, có vịt đàn... Ở đó có thể thiết kế bàn ghế ngồi thích hợp, bếp củi, nồi đun nước, nước sạch, lá vối trên cây. Du khách tự hái lá vối, tự rửa, tự đun, tự uống (có bảng chỉ dẫn, hướng dẫn cho du khách), tự trả tiền tự nguyện vào Self-money box (hộp nhận tiền tự nguyện). Cạnh đó thiết kế, đặt các Cọn nước truyền thống hoạt động tải nước lên ruộng để tạo không gian cảnh quan cho khách ngắm nhìn, chụp ảnh, tạo ra "Kinh tế nút bấm: economic click" sẽ kéo theo nhiều thay đổi khác...

- Xây dựng hệ thống giao thông đường thủy trên hồ thủy điện Tuyên Quang bằng việc xây dựng 2 bến thủy trên cơ sở nghiên cứu vị trí, quy hoạch quy mô bài bản. Xây dựng cảng đường thủy nội địa đúng quy hoạch, mang đặc trưng của cảng sông - hồ. Hoạch định các lộ trình, kết nối và chuyển tiếp lộ trình vận chuyển khoa học, hợp lý bằng việc phối kết hợp giữa vận chuyển đường thủy và vận chuyển đường bộ để phối hợp hai loại phương tiện vận chuyển này phục vụ du khách hợp lý, hiệu quả, tạo ra sự thay đổi khác biệt.

- Tổ chức mời các chuyên gia trong lĩnh vực giao thông vận tải để thiết kế đóng các loại tàu chở khách du lịch trên hồ thủy điện Tuyên Quang có kiểu dáng, kích thước, hình khối đường nét, sơn màu mang phong cách đặc trưng, khoa học, hợp lý, hài hòa, đẹp, ấn tượng. Trên tàu/thuyền trang bị hệ thống âm thanh phù hợp phục vụ thông tin, giải trí.

- Phát triển giao thông nội vùng liên hoàn, phù hợp bằng các loại đường bê tông cho giao thông nông thôn. Ven các trục đường giao thông, ở các vị trí có không gian thích hợp cần xây dựng hệ thống biển báo, biển chỉ dẫn khoa học, mỹ thuật, kỹ thuật, ấn tượng dễ nhận biết, dễ quan sát, dễ nhớ... Có thể đổi tên các "Bản Du lịch cộng đồng" thành các "Bản Văn hóa Du lịch" bởi vì bản chất của quá trình kinh doanh du lịch tại các bản Du lịch cộng đồng hiện nay chính là Văn hóa Du lịch: Khai thác, phát huy các giá trị của Văn hóa tộc người phục vụ phát triển du lịch và Phát triển du lịch, kinh doanh các dịch vụ phục vụ du khách mang phong cách, đặc trưng văn hóa tộc người. Xây dựng, cắm các biển chỉ dẫn Homestay đẹp, đem đến hình ảnh đặc trưng Lâm Bình, phong cách ấn tượng, thu hút sự chú ý của du khách và người đi đường. Trên biển có thể ghi thông tin cơ bản giúp mọi người có thể liên hệ trực tiếp ngay, biến mỗi biển chỉ dẫn trở thành phương tiện cung cấp thông tin, chào bán sản phẩm, mời gọi sử dụng dịch vụ chứ hiện nay chúng mới chỉ mang chức năng các tấm "biển chỉ đường".

\subsection{Phát triển các co sở lưu trú đăc biêt}

Với Du lịch Lâm Bình cần thiết phải phát triển các cơ sở lưu trú phù hợp để phục vụ du khách. Trước hết cần phải xác định: Các cơ sở lưu trú cho khách du lịch trên địa bàn huyện Lâm Bình sẽ hình thành hai loại cơ sở lưu trú chính:

1) Cơ sở lưu trú mang tính nghi duõng, hương thu dịch vụ

2) Co sở lưu trú mang tính thẩm nhận, trải nghiệm văn hóa

Với các cơ sở lưu trú dành cho khách nghỉ dưỡng, hưởng thụ sẽ là các khách sạn, nhà nghỉ trên hồ thủy điện Tuyên Quang. Nếu trước đây nhạc sĩ Phó Đức Phương có bài hát "Hồ trên núi" rất nổi tiếng thì những người kinh doanh du lịch hiện nay phải "sáng tác" ca khúc "Núi trên hồ" bằng việc nghiên cứu, kêu gọi các nhà đầu tư vào khai thác các đảo trên hồ, xây dựng các khách sạn, các khu resort trên hồ với kiến trúc độc đáo, đặc sắc với dịch vụ đặc trưng mang tính giải trí, nghỉ dưỡng cao cấp.

Tại khu vực lòng hồ có các khách sạn, nhà nghỉ có thể tổ chức các sự kiện thể thao - văn hóa mặt nước đặc trưng như các cuộc thi chèo thuyền Kayak, thi bơi, lặn. Nghiên cứu để phát triển loại hình thể thao mặt nước như lướt ván, dù bay, dù lượn.v.v... Khảo sát để xây dựng một vài bãi tắm trên hồ ở sườn của những quả đồi đất thấp ngập chìm trong nước lòng hồ. Cần thiết phải khảo sát lặn hồ để đánh giá hiện trạng, mức độ nguy hiểm; có thể vận chuyển cát, đá suối về trải ở các bãi tắm này. Tổ chức cắm biển chỉ dẫn, bố trí con người và các phương tiện đảm bảo an toàn, cứu hộ, cứu nạn trợ giúp khách tắm để không xảy ra tai nạn nào dù là nhỏ nhất.

Với các cơ sở lưu trú mang tính thẩm nhận, trải nghiệm văn hóa chính là hệ thống Homestay trong các làng bản dân tộc. Tại các nhà nghỉ cộng đồng này phải giữ được đặc trưng của bản sắc dân tộc. Những nét riêng, bản sắc của văn hóa tộc người từ kiến trúc, điêu khắc truyền thống; ẩm thực truyền thống; trang phục truyền thống; lối sống, nếp sống truyền thống. Phải giữ đặc trưng bản địa ở "Phiên bản 2": phiên bản diến, phiên bản dành cho khách du lịch? Đó là bản sắc văn hóa được điều chỉnh ở một vài khía cạnh nào đó để kết nối truyền thống và hiện sinh mà vẫn giữ được bản sắc văn hóa tộc người nhưng có thể hội nhập với các đối 
tượng du khách, không lạc hậu, không tạo ra sự xung đột văn hóa giữa các đối tượng du khách với cư dân bản địa, giữa du khách với du khách....

Bên cạnh việc duy trì và phát triển các Homestay tại các thôn bản như hiện nay cần nghiên cứu, quy hoạch để xây dựng "Phố du lịch" ở khu vực trung tâm huyện lỵ Lâm Bình trên địa bàn xã Lăng Can hiện nay. Đó sẽ là khu vực tập trung xây dựng khu "phố bản" với các ngôi nhà được xây dựng với kiến trúc truyền thống mang bản sắc văn hóa tộc người. Kết hợp hài hòa, nhuần nhuyễn giữa truyền thống và hiện đại trong phong cách bài trí, lối sống, truyền thống, trang phục, ngôn ngữ, ẩm thực... mang phong cách đặc trưng của dân tộc Tày - Dao. Khu phố bản du lịch này sẽ có mô hình: Đường phố - xưởng, quán, nhà hàng nhà nghỉ lưu trú - khu vệ sinh - suối sau nhà. Các căn nhà, khu nhà trong khu phố bản du lịch này đòi hỏi phải được tính toán quy hoạch không gian hài hòa, hợp lý; thiết kế chu đáo, khoa học; xây dựng hệ thống xử lý rác, nước thải đồng bộ, liên hoàn để bảo vệ môi trường. Cái quan trọng nhất là tạo nên "Không gian phố bản đặc trung" không nơi nào có, khác với các nơi khác. Ở đây là nơi quy tụ, tập hợp bản sắc văn hóa tộc người trong một không gian xác định! Đây chính là nơi "Hội tụ \& Lan tỏa" của bản sắc văn hóa tộc người từ đó sẽ trở thành nơi "Hội tụ \& lan tỏa" các đối tượng du khách khi đến với Lâm Bình. Việc di chuyển các hộ dân cư về để xây dựng "phố du lịch" tương tự như kiểu di dân lòng hồ nhưng cần có cơ chế, chính sách đặc thù trên cơ sở lựa chọn với các tiêu chí đặc trưng để các gia đình đồng bào có thể phát triển kinh doanh theo hướng dịch vụ du lịch tập trung trong không gian "phố/bản du lịch" thay vì kinh doanh nhỏ lẻ ở các thôn bản như hiện nay.

\subsection{Xây dụng điểm check in Lâm Bình đăc chủng ấn tựng}

Cần tổ chức thi ý tưởng sáng tạo cấu hình điểm check in Lâm Bình trên địa bàn phố huyện Lăng Can gần với phố bản du lịch, tạo nên ấn tượng đặc sắc và sự liên hoàn hợp lý trong tạo dựng hình ảnh liên kết các công trình trong một chỉnh thể thống nhất. Logo biểu trưng, biểu tượng văn hóa của Lâm Bình là gì? cần có các cuộc thi ý tưởng sáng tạo của các nghệ sĩ điêu khắc, tạo hình để tạo nên điểm check in với cấu trúc hình khối, chất liệu, hình ảnh, sắc màu ấn tượng khiến cho du khách thích thú check in khi đến với Lâm Bình. Chọn một điểm cao thích hợp, điêu khắc hình tượng Trâu ấn tượng trở thành điểm check in ấn tượng khiến du khách không thể không tới; từ đó sẽ trở thành nơi thu hút, tập trung du khách khi đến với Lâm Bình. Trong không gian của khu vực điểm check in có thể nghiên cứu để phát triển các dịch vụ vui chơi giải trí, ẩm thực, thưởng thức nghệ thuật diễn xướng dân gian, chợ quê... phù hợp. Cũng trong không gian phố bản du lịch, điểm check in có thể nghiên cứu để phát triển phương tiện vận chuyển đặc thù mang ấn tượng và phong cách đặc trưng văn hóa của cư dân Lâm Bình: Có thể là xe trâu, xe ngựa kéo hay xe hình con Vịt đạp chân...

\subsection{Xây dụng nguồn nhân lục phục vụ du lịch mang phong cách đăc trưng}

Có chiến lược phát triển, xây dựng nguồn nhân lực phục vụ phát triển du lịch cho Lâm Bình trên cơ sở tổng thể. Từ việc ban hành cơ chế, chính sách ưu đãi nhằm "chiêu hiền đãi sĩ" tuyển dụng các sinh viên con em đồng bào các dân tộc quê hương Lâm Bình đã và đang học nghề du lịch ở Hà Nội, Tuyên Quang, Thái Nguyên... về làm việc tại quê hương.

- Liên kết phối hợp với các cơ quan quản lý, cơ sở đào tạo là các trường Đại học, cao đẳng nghề du lịch, các viện nghiên cứu, các doanh nghiệp, hiệp hội du lịch... cùng với các bộ phận chức năng của tỉnh Tuyên Quang, huyện Lâm Bình để tổ chức thường xuyên các đoàn Famtrip, khảo sát, tọa đàm khoa học tại thực địa. Các ý tưởng phát triển sản phẩm du lịch đặc trưng; những điều chỉnh trong đường lối, cơ chế, chính sách sẽ ra đời từ thực tế để đáp ứng yêu cầu cơ bản của hoạt động du lịch là "Thích ứng cao". Kết nối với các địa phương trong và ngoài nước để đưa các cán bộ chức năng, người dân tại các hộ kinh doanh homestay đi tham quan, khảo sát, học tập, rút kinh nghiệm mô hình phát triển du lịch của các địa phương; từ đó rút ra giải pháp phù hợp cho du lịch Lâm Bình.

- Tổ chức nhiều khóa tập huấn chuyên biệt dành cho cán bộ quản lý văn hóa - du lịch; dành cho các hộ dân kinh doanh homestay; dành cho các chủ tàu thuyền vận chuyển khách trên hồ; dành cho các hướng dẫn viên bản địa. Có thể phối hợp với các cơ sở đào tạo tổ chức các khóa đào tạo ngoại ngữ chuyên ngành cho người dân kinh doanh homestay...

\subsection{Sáng tạo văn hóa dân gian hiện đại đăăc sắc phục vụ phát triển du lịch}

- Xây dựng các nhóm, đội trình diễn nghệ thuật truyền thống: Khai thác giá trị của Then của người Tày, Páo dung của người Dao, Nhảy lửa của người Pà Thẻn trên cơ sở bàn bạc trao đổi, thảo luận để đưa ra phương cách khai thác, phục vụ du khách các loại 
hình nghệ thuật này ấn tượng, hiệu quả, có chất lượng. Cần sưu tầm những bài, điệu Then truyền thống; tuyển chọn diễn viên, luyện tập, công diễn phù hợp trong những không gian và thời gian nhất định phục vụ các đối tượng du khách xác định. Động thái này vừa góp phần "bảo tồn động" di sản văn hóa vừa đa dạng hóa sản phẩm du lịch đặc trưng trên đất Lâm Bình, tạo sự phát triển bền vững.

- Phát triển kho tàng tri thức dân gian bản địa trên cơ sở sáng tạo văn hóa dân gian hiện đại thông qua các "dữ liệu" là cảnh quan, không gian, môi trường hiện hữu có sự điều chỉnh nhất định bởi trí tuệ và bàn tay con người. Tổ chức các trại sáng tác văn học nghệ thuật sáng tác, sáng tạo các tác phẩm văn học, nghệ thuật, hội họa, các ca khúc... phục vụ du lịch Lâm Bình. Mời các nhà nghiên cứu văn hóa dân gian sẽ cải biên, bổ sung, sáng tạo những truyền thuyết dân gian mới, huyền thoại mới về Tài Ngào với các "hành trang", "phụ tùng" của Ngài miễn sao hợp lý. Ví dụ, khi đi thuyền trên khu vực Cọc Vài, hướng dẫn viên ngoài việc hướng dẫn, giải thích cho du khách về truyền thuyết liên quan đến Cọc Vài, có thể bổ sung câu chuyện về những chiếc lá cây huyền thoại trên đỉnh Cọc Vài, như sau:

"Huyền thoại về cây trên đỉnh Cọc Vài: Cọc Vài là tên một đảo đá nhỏ trên hồ Thuỷ điện Tuyên Quang có hình 1 chiếc cọc buộc Trâu và cũng có hình một sinh thực khí của giống đực. Cư dân nơi đây đồn thổi rằng, nếu ai đó chạm được vào Cọc Vài sẽ được hưởng những đặc ân do Trời ban cho: Nam thì sẽ khỏe mạnh, sung mãn! Nữ thì sẽ "ước gì được nấy"! Trên đỉnh cọc Vài cây cối tốt tươi, rậm rạp, chả biết là cây gì nhưng cư dân ở đây mà trực tiếp là mấy anh công an đường thuỷ huyện Lâm Bình nói với tôi rằng: lá cây trên đỉnh nấu nước uống sẽ rất tốt cho sức khoẻ giới tính của nam giới. Nhưng vì Cọc Vài cao quá, hiểm trở quá chẳng ai leo được lên đỉnh hái lá về dùng. Có nhà nọ trong vùng, anh chồng ốm nheo nhách trong khi chị vợ lại đang thì hồi xuân, tái sắc, bừng bừng khí thế. Cho nên, chị vợ bèn tự mình đi mua cây súng kíp, ngày đêm luyện tập bắn đến độ "bách phát bách trúng". Thế rồi 1 ngày kia chị chàng bơi thuyền ra chân Cọc Vài, vác súng ra ngắm chọn cành lá tốt tươi nhất của cây trên đỉnh Cọc Vài bắn đòm 1 phát. Chiếc lá tươi rời cành, chao đảo trong không trung khiến chị chàng khấp khởi mừng thầm, bụng bẩu dạ: "Phen này chết với bà!". Ai dè chiếc lá mới rời cành chao trong không trung được vài 3 cái đã có một con chim ở đâu lướt tới cắp vào mỏ và bay đi mất! Chị chàng bực tức nghiến răng rủa chửi thầm con chim "Tổ cha mày chim ợ! để bà mang về cho chim của bà chứ...". Chị chàng tiếp tục bắn thêm vài phát nữa đều như vậy: lá rụng, chim ở đâu lại lao tới cắp đi mất. Hết đạn vẫn trắng tay, chị chàng tức giận kê gối bẻ đôi cây súng ném xuống hồ kèm theo câu chửi: "Tổ cha chúng mày, chưa được lá nào đã hết đạn, súng với chả ống, Chim với chả chóc!" rồi hầm hầm đi về. Từ đó đến nay, những người đàn ông trong vùng (nhất là mấy chú công an ở Bến Thủy, Lâm Bình) thường ngày đều bơi thuyền đến chân Cọc Vài, hóng lên mong một chiếc lá vàng trên đỉnh rớt xuống để mang về nhà nhóm lửa Hạnh phúc. Vậy mà có thấy ai được bao giờ? Ai giỏi, ai muốn, mang súng lên Lâm Bình - Na Hang bắn lá chơi xem bọn chim có cắp mất không nào?".

Ngồi trên xe vượt qua đèo Khau Lắc để vào cửa ngõ Lâm Bình, hướng dẫn viên ứng khẩu đọc cho du khách câu ca, hứa hẹn mọi người sắp được thăm thú một vùng non nước hữu tình:

\section{Muốn thăm cảnh đẹp Lâm Bình,}

Vượt đèo Khau Lắc chúng minh cùng đi.

- Khảo sát cụ thể, chi tiết lòng hồ thủy điện Tuyên Quang để khi đi tàu thuyền thăm thú cảnh quan trên hồ Thủy điện Tuyên Quang, phải dừng lại ở những vị trí đắc địa có thể quan sát địa hình, địa vật đặc sắc, đặc trưng mang ấn tượng cho du khách. Ở đó tổ chức thi sáng tác, đặt tên gọi các khu vực, địa hình địa vật làm nổi bật đặc trưng, dễ hiểu, dễ nhớ cho du khách, như "Bãi cọc Bạch Đằng" ở Bản Phủng, "Hòn con chó", "Hòn tự tình", "Thác khe noọng"... thuộc khu vực xã Khuôn Hà bên cạnh những Cọc Vài, thác Khuổi Nhi đã có.v.v... Tiến hành tập huấn cho những chủ tàu thuyền, người lái tàu, đội ngũ hướng dẫn viên về các điểm nhấn trên lộ trình tham quan trên lòng hồ. Thuyền sẽ đi theo lộ trình nào, chỗ nào đi nhanh, chỗ nào đi chậm, dừng lại chỗ nào để có góc nhìn đặc tả? Ở những điểm nhấn ấy, chủ thuyền, hướng dẫn viên sẽ hướng dẫn cho du khách, "định hướng tư duy", "áp đặt hình tượng" cho du khách với 3 hướng tiếp cận chính: Tu duy Thần tiên - Tu duy linh vật \& Tu duy phồn thực. Nhờ các Nhiếp ảnh gia sẽ chọn các điểm check in, tàu/thuyền chở khách du lịch khi đến đó sẽ dừng để cho du khách chụp ảnh: buổi sáng thì chụp Cọc Vài từ hướng nào, ở chỗ nào thì đẹp? Buổi chiều chụp Cọc Vài từ hướng nào, chỗ nào thì đẹp... Những cách tiếp cận như vậy sẽ góp phần tạo ra sự phát triển của "Economic click" - Kinh tế nút bấm, góp phần quảng bá cho Du lịch Lâm Bình, Du lịch Tuyên Quang. 


\section{6. Ầm thục và mua sắm sản vật đặc sản của Lâm Bình}

Lâm Bình hiện đang có nhiều món ăn, đồ uống ngon - bổ - rẻ. Trên nền tảng truyền thống này hướng tới phát triển phục vụ khách du lịch, cần phải làm thay đổi trong chế biến, bài trí sắp đặt các món ăn - đồ uống này theo tiêu chí mới phục vụ khách du lịch, để đạt được 5 nội dung, gồm: Ấn tượng - Ngon - Bổ Phù hợp - Thuận tiện: Hình ảnh và phong cách phục vụ, giao lưu, giao tiếp ấn tượng - Ăn ngon miệng Chất lượng bổ - Giá cả phù hợp - Thanh toán, mua sắm mang về mang đi thuận tiện. Nghiên cứu, sưu tầm, tổng hợp trong dân gian, từ các nghệ nhân dân gian ở các cộng đồng cư dân làng bản, hình thành những nơi cung cấp nguyên liệu đặc trưng, tập hợp các cách chế biến đặc trưng; bổ sung mẫu mã, hình thức bài trí món ăn; tạo tác các đồ dùng vật dụng chứa đựng, bảo quản, lưu thông thuận tiện cho du khách... Du khách không chỉ mang về ấn tượng, họ cần phải mang về cho họ, người thân và gia đình của họ những món quà, sản vật có ý nghĩa, có giá trị và có sức hấp dẫn cao. Tất cả để hướng tới việc chuyển đổi ngành nghề, tái cơ cấu kinh tế địa phương, tăng xuất khẩu tại chố! Đó là gì?

\subsection{Bảo vệ môi truờng du lịch đăăc hũu}

Môi trường du lịch quyết định thành công kinh doanh du lịch. Muốn du lịch Lâm Bình phát triển bền vững, ngay từ bây giờ khi bắt đầu phát triển, cần phải giữ vững và bảo vệ môi trường du lịch thật tốt. Lâm Bình - những cánh rừng bình yên; cán bộ và nhân dân Lâm Bình đã và đang giữ được rừng rất tốt; đó thực sự là tài sản, là tài chính cho kinh tế du lịch. Đó chính là tài nguyên, nguyên liệu xanh, nguyên liệu sạch cho công nghiệp Du lịch; là điều đặc biệt mà Lâm Bình không dễ gì có được. Hiện trạng này tiếp tục phải được giữ vững và phát triển để môi trường tự nhiên cùng môi trường văn hóa Lâm Bình đem lại môi trường sống tốt cho người dân Lâm Bình; đem lại môi trường đặc hữu, đặc biệt, có nhiều giá trị cho du lịch phát triển. Phong cảnh làng quê yên bình, đường thôn, ngõ bản được trải bê tông sạch sẽ, rộng rãi. Cảnh sắc quê hương phong quang, tốt tươi, yên bình. Khí hậu trong lành sạch sẽ, mát mẻ... Thái độ, tình cảm từ người dân đến cán bộ các cấp đều rất thân thiện, chu đáo, nhiệt tình, trách nhiệm. Hạn chế và hướng tới một

Lâm Bình không rác thải nhỵa! Đó sẽ là những tài sản vô giá của Lâm Bình để phát triển du lịch bền vững. Chúng ta có quyền kỳ vọng về điều này!

\section{TÀI LIỆU THAM KHẢO}

1. Bộ Chính trị Đảng Cộng sản Việt Nam (2017), Nghị quyết 08-NQ/TW của Bộ Chính trị Đảng Cộng sản Việt Nam về phát triển du lịch trở thành ngành kinh tế mũi nhọn, ban hành ngày 16/01/2017.

2. Bộ Văn hóa, Thể thao và Du lịch; Tổng cục $\mathrm{Du}$ lịch (2013), “Quy hoạch tổng thể phát triển du lịch Việt Nam đến năm 2020, tầm nhìn đến năm 2030", H.2013.

3. Luật Du lịch số 09/2017/QH14, Quốc hội nước CHXHCN Việt Nam ban hành ngày 19/06/2017.

4. Luật Di sản Văn hóa và nghị định huoóng dẫn thi hành (2002), NXB Chính trị Quốc gia, H.2002.

5. Lê Hồng Lý (chủ biên), Dương Văn Sáu, Đặng Hoài Thu (2010), giáo trình “Quản lý di sản văn hóa với phát triển du lịch”, NXB Đại học Quốc gia Hà Nội, H.2010.

6. Đổng Ngọc Minh, Vương Lôi Đình (2001), Kinh tế du lịch và Du lịch học, NXB Trẻ. 2001.

8. Dương Văn Sáu (2017), Giáo trình Di tích lịch sủ - văn hóa và danh thắng Việt Nam, Tái bản có sửa chữa bổ sung lần 1, Nxb Lao Động, Hà Nội 2017.

9. Dương Văn Sáu (2018), Giáo trình Lễ hội Việt Nam trong sụ phát triển du lịch, Tái bản có sửa chữa bổ sung lần 1, Nxb Lao Động, Hà Nội 2018.

10. Dương Văn Sáu (2019), Giáo trình Văn hóa $\mathrm{Du}$ lịch, Tái bản có sửa chữa bổ sung lần $1, \mathrm{Nxb}$ Lao Động, Hà Nội 2019.

11. Sở Văn hóa, Thể thao \& Du lịch Tuyên Quang (2009), Du lịch Tuyên Quang, Nxb Thông tấn, Hà Nội 2009.

12. https://www.lambinh.tuyenquang.gov.vn 


\section{Basic issues to develop Lam Binh tourism}

Duong Van Sau

\section{Article info}

Recieved:

12/11/2019

Accepted:

$10 / 3 / 2020$

Keywords:

Lam Binh tourism;

Lam Binh tourism

developmet

\begin{abstract}
Lam Binh - a mountainous, deep-lying, remoting and highland district of Tuyen Quang province with many rich resources to exploit for tourism development. So far, Lam Binh Tourism has not developed. It is a challenge and a great opportunity for the district's tourism economy to develop. At the developing gateway, Lam Binh tourism needs to take precise, firm, long-term strategic steps and adaptive policy mechanisms to attract investment and create fundamental changes. In major areas: Waterway transport - Tourism accommodation facilities - Building typical tourism products - Training to improve the quality of human resources - Synchronous development links ... These are weak determinants of the development for Lam Binh Tourism in the immediate future as well as long term.
\end{abstract}

